\title{
Bio-treatment of phosphate from synthetic wastewater using Pseudomonas sp YLW-7
}

\author{
* USHARANI, K; LAKSHMANAPERUMALSAMY, P \\ Division of Environmental Microbiology, Department of Environmental Sciences, \\ Bharathiar University, Coimbatore - 641 046. TN, India \\ *Corresponding author: E.mail: usharaniks2003@yahoo.com
}

\begin{abstract}
In this study, the efficient phosphate utilizing isolates were used to remove phosphate from synthetic phosphate wastewater was tested using batch scale process. Hence the objective of the present study was to examine the efficiency of bacterial species individually for the removal of phosphate from synthetic phosphate wastewater. The most efficient phosphate reducers were isolated and screened from eutrophic lake water samples. The total heterotrophic bacterial analysis of the samples showed the presence of about 22 phosphate reducers. Among them, Pseudomonas sp YLW-7 were found to be efficient in phosphate reduction based on the maximum phosphate ultization which was observed by plate screening method using the minimum inhibitory concentration (MIC) test. The effect of carbon sources (glucose, starch, sucrose and lactose) at $0.5 \%$ on the removal of phosphate by Pseudomonas sp YLW7 was estimated. The maximum growth of Pseudomonas sp YLW7 was observed to be 0.9886 OD in glucose followed by starch $(0.9456$ OD), Sucrose $(0.9095$ OD) and lactose $(0.8407$ OD). The pH change in culture medium after $72 \mathrm{~h}$ treatment was found to be 6.0 in glucose, starch, lactose sources and 5.8 in sucrose carbon source. The phosphate removal was observed to be maximum of $68 \%$ in synthetic phosphate wastewater with glucose carbon source followed by starch $(66 \%)$, sucrose $(65 \%)$ and lactose $(62 \%)$ after $72 \mathrm{~h}$ at neutral $\mathrm{pH}(7.0 \pm 2)$ by Pseudomonas sp YLW-7. Thus the Pseudomonas sp YLW-7 may use the contaminants as nutrients source and might be used in the remediation of phosphate contaminated environments. @ JASEM
\end{abstract}

The addition of phosphorus as phosphate ion is one of the most serious environmental problems because of its contribution to the increased eutrophication process of lakes and other natural waters. The possible entry of this ion into aquatic environment is through household sewage water and industrial effluents- particularly fertilizer and soap industries. Nitrogen and phosphorus are the primary causes of cultural eutrophication (i.e., nutrient enrichment due to human activities) in surface waters. The most recognizable manifestations of this eutrophication are algal blooms that occur during the summer. Chronic symptoms of over-enrichment include low dissolved oxygen, fish kills, murky water, and depletion of desirable flora and fauna. In addition, the increase in algae and turbidity increases the need to chlorinate drinking water, which, in turn, leads to higher levels of disinfection by-products that have been shown to increase the risk of cancer. Excessive amounts of nutrients can also stimulate the activity of microbes, such as $P$ fisteria, which may be harmful to human health (U.S. EPA, 2001). Approximately $25 \%$ of all water body impairments are due to nutrient-related causes (e.g., nutrients, oxygen depletion, algal growth, ammonia, harmful algal blooms, biological integrity, and turbidity) (U.S. EPA, 2007). In efforts to reduce the number of nutrient impairments, many point source dischargers have received more stringent effluent limits for nitrogen and phosphorus. To achieve these new, lower effluent limits, facilities have begun to look beyond traditional treatment technologies. An important group of contaminants for which efficient treatment methods are needed are phosphates, since they may adversely affect and pose a threat to aquatic ecosystems. According to federal government standards, phosphate levels in water should not exceed $0.01-0.1 \mathrm{mgl}^{-1}$ (EPA, 1991).
Therefore it is essential to control the emission of phosphates from discharge of wastewater and reducing phosphorus concentrations to the lowest possible level is vital to the maintenance of unpolluted water supplies.

Biotreatment is a cost-effective method for wastewater before being discharged into the streams and rivers. Microbial strategies for the removal of environmental pollutants from waste streams or contaminated sites can provide an attractive alternative to traditional methods such as incineration or disposal in landfills. Currently, phosphates are biologically removed by wastewater treatment facilities by absorption of dissolved orthophosphate, polyphosphate and organic phosphate by living microorganisms, such as bacteria, microalgae, yeast, protozoa, fungi, and macrophytes. Hence the objective of the present study was to examine the efficiency of individual bacterial species isolated from eutrophic lake water for the removal of phosphate from wastewater.

\section{MATERIALS AND METHODS}

Sample Collection: The eutrophic lake waters were collected in sterile glass bottles from four different sampling stations of Yercaud and Kodaikanal Lakes (Tamil Nadu, South India).

Isolation and identification of phosphate reducers: Pour plate technique was employed to enumerate total heterotrophic bacteria using Nutrient Agar (Hi-Media, Mumbai, India). Minimum inhibitory concentration (MIC) test with plate screening method was carried out to screen phosphate reducers using phosphate agar. The bacterial cultures isolated from nutrient agar and phosphate agar plates were classified to various 
genera based on their morphological and biochemical characters as given in Bergey's Manual of Determinative Bacteriology (Buchanan and Gibbons, 1994). The phosphate reducers screened from the different sample source were given symbols (code name) based on the source of isolation; Kodaikanal Lake Water- KLW, Yercaud Lake Water - YLW.

Preparation of inoculums: Nutrient broth (Hi-Media, Mumbai, India) was prepared and selected bacterial isolates were inoculated separately and incubated for $24 \mathrm{~h}$ at room temperature. The cells were recovered by centrifugation $(10,000 \mathrm{rpm}$ for $15 \mathrm{~min})$ and were transferred to sterile saline. The cell concentration of each strain was adjusted to an optical density at 600 $\mathrm{nm}$ (OD $\left.{ }_{600}\right)$ of 0.1 and used as inoculum. The efficient phosphate reducers (Pseudomonas sp YLW7) were used for removal of phosphate. About 105 (YLW-7) X $10^{4} \mathrm{CFU} / 100 \mathrm{ml}$ (1ml of $0.1 \mathrm{OD}$ ) of the cells was used as an inoculum.

Experimental study: Shake flask batch culture experiments were performed. Phosphate removal was carried out by adding phosphate to synthetic wastewater (mineral salts dissolve in plain distilled water with phosphate concentration of $100 \mathrm{mgl}^{-1} ; \mathrm{pH}$ 7.2) and $0.5 \%$ of different carbon substrates such as sucrose, starch, glucose and lactose were prepared. Phosphate was added to the medium as $\mathrm{KH}_{2} \mathrm{PO}_{4}$ and $\mathrm{K}_{2} \mathrm{HPO}_{4}$ at a 1.2:1 weight ratio to obtain $\mathrm{P}$ concentrations of $100 \mathrm{mg} /$ liter. The nutrient solution contained (per liter) $1.5 \mathrm{~g}$ of $\mathrm{FeCl}_{3} 6 \mathrm{H}_{2} \mathrm{O}, 0.15 \mathrm{~g}$ of $\mathrm{H}_{3} \mathrm{BO}_{3}, 0.03 \mathrm{~g}$ of $\mathrm{CuSO}_{4} 5 \mathrm{H} 2 \mathrm{O}, 0.18 \mathrm{~g}$ of KI, $0.12 \mathrm{~g}$ of $\mathrm{MnCl}_{2} 4 \mathrm{H}_{2} \mathrm{O}, 0.06 \mathrm{~g}$ of $\mathrm{Na}_{2} \mathrm{MoO}_{4} 2 \mathrm{H}_{2} \mathrm{O}, 0.12 \mathrm{~g}$ of $\mathrm{ZnSO}_{4} 7 \mathrm{H}_{2} \mathrm{O}, 0.15 \mathrm{~g}$ of $\mathrm{CoCl}_{2} 6 \mathrm{H}_{2} \mathrm{O}$, and $10 \mathrm{~g}$ of EDTA. Then the medium containing flasks were sterilized at $121^{\circ} \mathrm{C}$ and at $15 \mathrm{lbs}$ for $15 \mathrm{~min}$ in an autoclave. One $\mathrm{ml}$ of inoculum (0.1 OD) from the selected phosphate reducers (Pseudomonas sp YLW7) was inoculated in the individual flasks. They were incubated at room temperature in a shaker maintained at $150 \mathrm{rpm}$ for a period of three days. Samples were collected at $0,24,48,72 \mathrm{~h}$ and analyzed for growth of bacteria, $\mathrm{pH}$ change and change in total phosphate concentration of the medium. All experiments were performed in triplicates.

Growth of bacteria and $p H$ change: The increase in growth of bacteria for every $24 \mathrm{~h}$ was monitored by measuring OD at $600 \mathrm{~nm}$ on a UV-Visible Spectrophotometer (UV-VIS Hitachi - U3210). The $\mathrm{pH}$ change in the culture medium after treatment was measured using a $\mathrm{pH}$ meter.

Estimation of phosphate: The phosphate uptake activities of different strains were quantified by stannous chloride reduced molybdophosphoric acid blue method. The soluble phosphate content in the culture medium was estimated after 24,42 , and $72 \mathrm{~h}$ of incubation by using the stannous chloride calorimetric method (Saxena, 1994) and (APHA, 1998). After every $24 \mathrm{~h}, 10 \mathrm{ml}$ of the agitated sample was drawn from the series of individual flask and transferred into the centrifuge tubes of $15 \mathrm{ml}$ capacity under aseptic conditions. Then the tubes containing samples were centrifuged at $10,000 \mathrm{rpm}$ at $15 \mathrm{~min}$ and the clear supernatant was used for soluble phosphate estimation at $690 \mathrm{~nm}$ by using spectrophotometer (UV-VIS Hitachi - U3210). Phosphate uptake efficiency (E) was calculated using the formula, $\mathrm{E}=[(\mathrm{I}-\mathrm{F}) / \mathrm{I}] \mathrm{x} 100$ Where, $\mathrm{I}$ and $\mathrm{F}$ are the initial and final concentrations of phosphorous respectively. An efficiency value of $100 \%$ was obtained when no phosphate appeared in the water sample (i.e., $\mathrm{F}=0$ ).

\section{RESULTS AND DISCUSSION}

The isolation and screening of phosphate reducers from the samples mentioned above were carried out to determine the efficient phosphate removal which showed that wide range of these bacteria was occurred in eutrophic lake water. Table. 1 shows the maximum population of total heterotrophic bacterial (THB) population of $28.5 \mathrm{CFU} \times 10^{3} \mathrm{ml}^{-1}$ and phosphate reducing bacterial population of 3.3 CFU $\mathrm{x}$ $10^{3} \mathrm{ml}^{-1}$ was noticed in Yercaud lake water sample. It was found that among the 22 isolates, Pseudomonas sp (YLW-7) was screened and identified as predominant phosphate utilizers based on the minimum inhibitory concentration (MIC) test after 72 $\mathrm{h}$ of incubation, Yercaud Lake Water-YLW as in Fig.1. These isolates were used in this study to remove phosphate in synthetic phosphate wastewater. Phosphate utilizing bacteria were known to be present in various environments (Illmer and Schinner, 1992) and (Illmer et al., 1995). The removal efficiency of soluble phosphates varied with strains. Various microorganisms are capable of utilizing phosphate as a sole source carbon or phosphorus (Malacinski et al., 1967) and these microbial transformations have been proposed as key steps in the phosphorous cycle in nature.

Table.1 Enumeration of Total heterotrophic bacteria (THB) and Phosphate reducers

present in different samples

\begin{tabular}{lll}
\hline $\begin{array}{l}\text { Source of } \\
\text { Isolation }\end{array}$ & THB Population & $\begin{array}{l}\text { Phosphate } \\
\text { reducers }\end{array}$ \\
\hline $\begin{array}{l}\text { Kodikanal } \\
\text { Lake Water } \\
\text { (KLW) }\end{array}$ & $17.8{\mathrm{cfu} \times 10^{3} \mathrm{ml}^{-1}}^{2.2 \mathrm{cfu} \times 10^{3}}$ & $\begin{array}{l}\mathrm{ml}^{-1} \\
\text { Yercaud Lake } \\
\text { Water (YLW) }\end{array}$ \\
\hline
\end{tabular}

The growth of bacterial species was analyzed using different carbon sources in phosphate medium after $72 \mathrm{~h}$ of incubation period. In synthetic phosphate wastewater with $0.5 \%$ carbon sources, the individual 
strain of Pseudomonas sp YLW7 was observed a maximum growth of $0.9886 \mathrm{OD}$ in glucose followed by starch (0.9456 OD), Sucrose (0.9095 OD) and lactose (0.8407 OD) as in Fig.2. The phosphate was taken up by cells for growth and to reform polyphosphate under aerobic condition. Increase in biomass concentrations showed a greater phosphate uptake capacity and enhances the efficiency of phosphate removal.

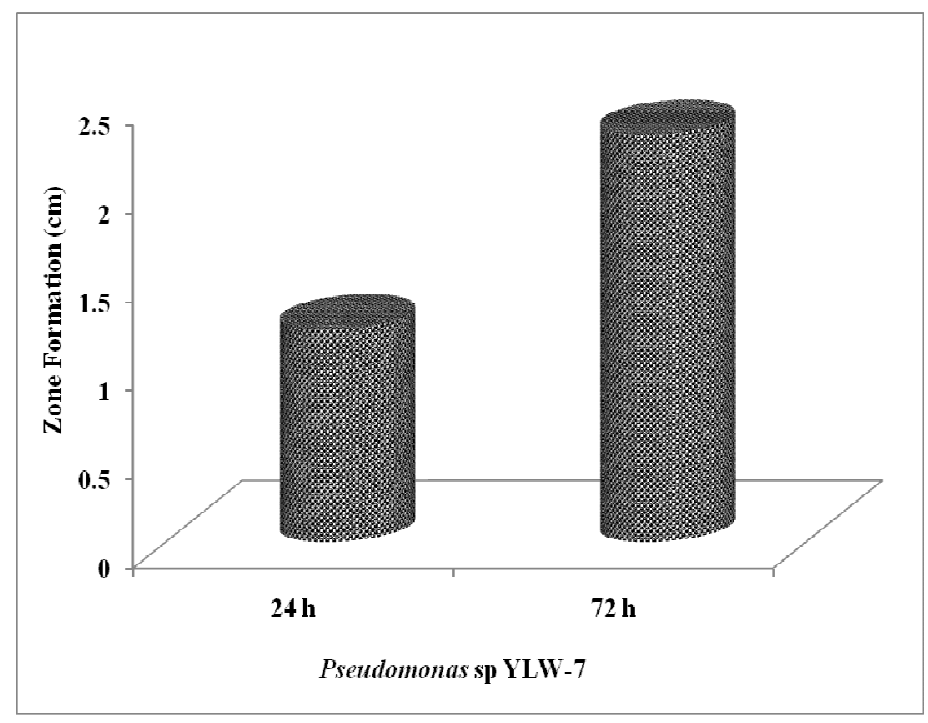

Fig.1. Screening of efficient phosphate reducers based on the Minimum Inhibitory Concentration test (Pseudomonas sp YLW-7)

In order to find the relationship between metabolic activities and reduction of phosphate, $\mathrm{pH}$ of the culture medium was monitored. The $\mathrm{pH}$ change in culture medium from the initial $\mathrm{pH} 7$ after $72 \mathrm{~h}$ was found to be 6.0 in glucose, starch, lactose and 5.8 in sucrose carbon source as in Fig.3. The $\mathrm{pH}$ value of the culture medium with $0.5 \%$ of carbon source was reduced during the process. In contrast, there is no significant change of $\mathrm{pH}$ was monitored in the medium without carbon source. The culture medium, pH 6.0 was favored for acid phosphatase secretion was reported (Bouquet et al., 1987). Burkholderia cepacia maximum phosphate removal and accumulation of polyphosphate at $\mathrm{pH} 5.5$ reported (Mullan et al., 2002). In contrast, high phosphate utilization was observed without detectable $\mathrm{pH}$ change (Asea et al., 1998).

In synthetic phosphate wastewater with $0.5 \%$ carbon source, the Pseudomonas YLW-7 showed maximum phosphate removal of $68 \%$ when compared to control in glucose carbon source followed by starch $(66 \%)$, sucrose $(65 \%)$ and lactose $(62 \%)$ as in Fig.4. Among the carbon sources, the glucose source showed maximum phosphate removal $(68 \%)$ by the Pseudomonas sp in synthetic phosphate wastewater at initial $\mathrm{pH} 7$, the glucose may be oxidized to gluconate which is further converted to other compounds. Glucose carbon source could induce good enhanced biological phosphate removal performance reported (Jeon and Park, 2000). The carbon, i.e. glucose is oxidized to gluconate, which is converted into other compounds, such as 2-keto-3-deoxygluconate, pyruvate or glyceraldehydes was reported (Kim et al, 1998) and (Reyes et al., 1999). Kim et al (1998) suggested that the presence of organic acids (formate) and the mechanism such as the release of protons associated with biological ammonium assimilation that enhances the utilization of phosphates. In synthetic phosphate solution at $100 \mathrm{mgl}^{-1}$ of phosphate concentration in $0.5 \%$ carbon source, it was found to be maximum removal of $68 \%$ with maximum growth of $0.9886 \mathrm{OD}$ at initial $\mathrm{pH} 7.0 \pm 2$, by Pseudomonas sp in glucose carbon source (Fig. 5). The results showed that the strain could grow rapidly and remove phosphate efficiently in synthetic phosphate solution with $0.5 \%$ carbon source.

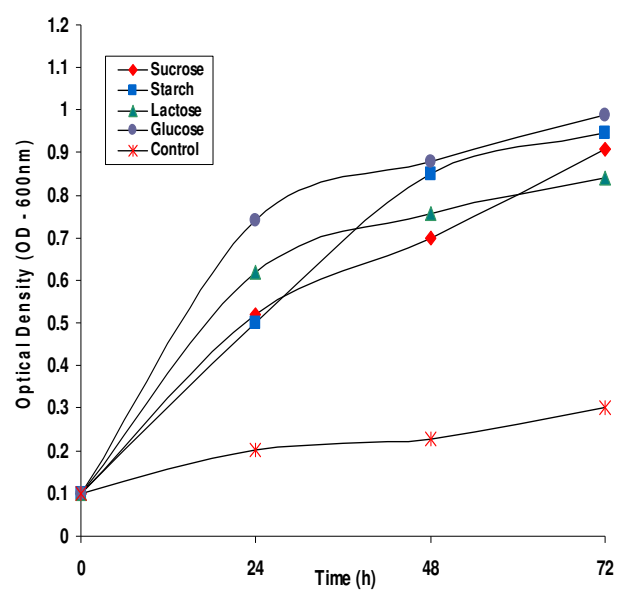

Fig.2 Effect of carbon source on the growth of Pseudomonas sp YLW-7 in synthetic phosphate wastewater 


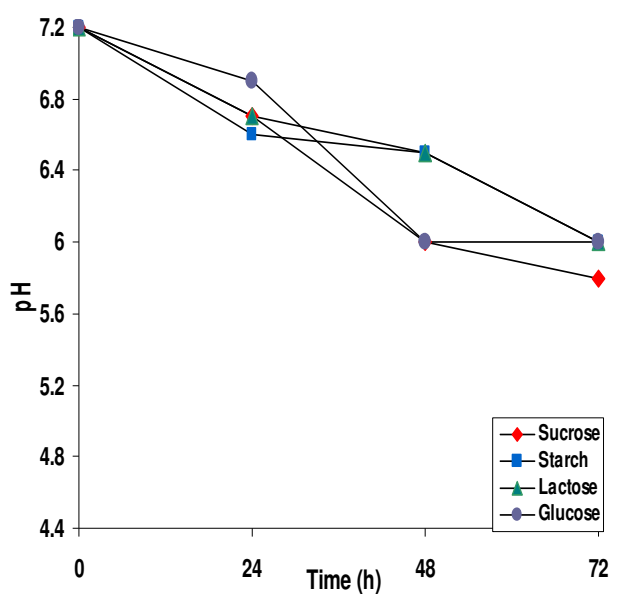

Fig.3 Change in $\mathrm{pH}$ of culture medium (synthetic phosphate wastewater) during phosphate removal by Pseudomonas sp YLW-

Carbon source - enriched synthetic phosphate solution at the experimental concentrations enhances the phosphate removal and greatly influenced the growth of bacteria. The carbon source was provided in the medium in order to enrich synthetic medium which in turn enhance the growth and phosphate uptake capacity of bacteria. Bacteria which can accumulate phosphate in the aerobic conditions and their internal phosphate had been depleted under anaerobic conditions. These bacteria use the stored carbon reserves to produce energy for growth and to replenish their stores of polyphosphate. The accumulated polyphosphate is assumed to be an energy source for substrate assimilation during anaerobic growth conditions and poly- $\beta$ hydroxyalkanoate (PHA) synthesis. Evidence suggests that degradation of polyphosphate may be used to regulate intracellular $\mathrm{pH}$ under alkaline conditions (Seviour et al., 2003). The result is a net removal of phosphate from the wastewater. The genes and proteins of microbial cells involved in the hydrolysis of organic phosphates were observed (Torriani-Gorini, 1987). Some microorganisms can accumulate phosphate as polyphosphate (Kornberg.a., 1995) and (Keasling and Hupf, 1996).

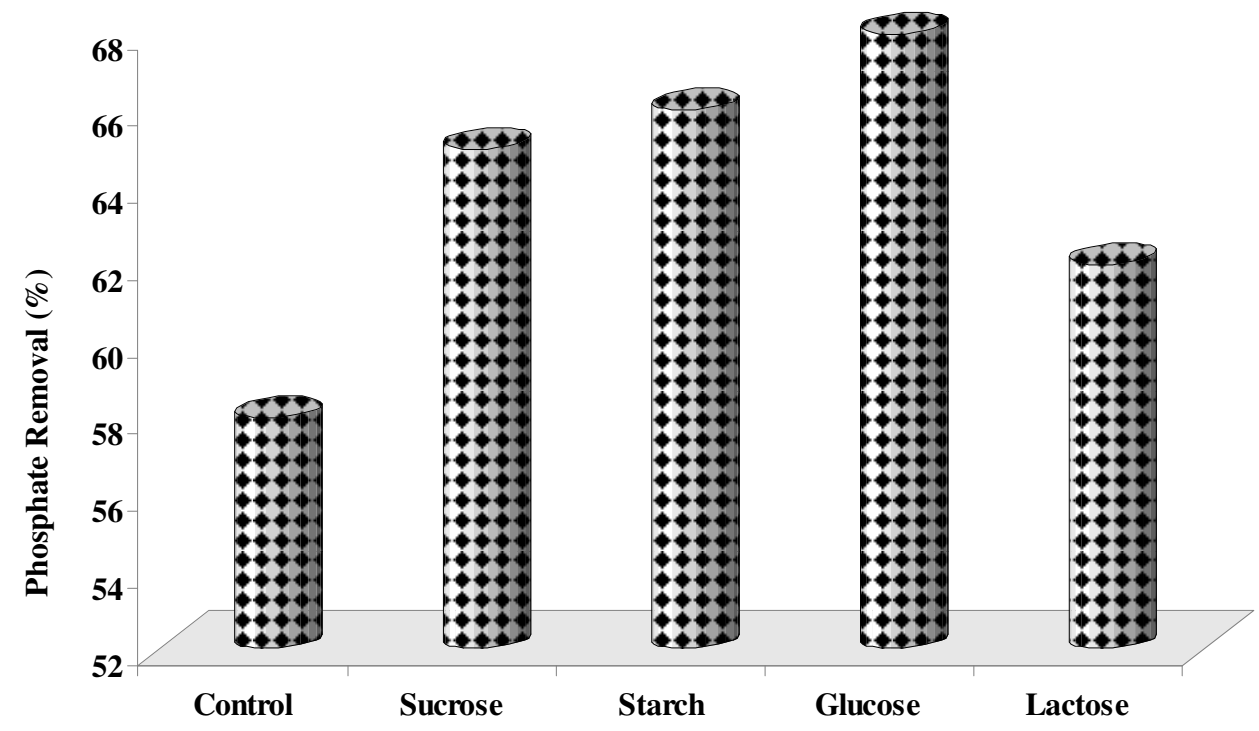

Fig.4 Effect of carbon source on the removal of phosphate by Pseudomonas spYLW-7 in synthetic phosphate wastewater

The results from this study conclude that the synthetic phosphate wastewater with carbon sources showed maximum phosphate removal when compared to without carbon source. The phosphate could be reduced below the permissible limit as prescribed by Environmental Protection Agency (EPA, 1991). Thus the bacterial isolates Pseudomonas sp YLW-7 of the present study was found to have potential in phosphate removal and can be recommended for biotreatment of phosphate wastewater. Thus the Pseudomonas sp YLW-7 may use the contaminants as nutrients and as energy sources or it may be utilized by co-metabolism. Hence the bacterial isolate Pseudomonas sp YLW-7 could be used in the remediation of phosphate contaminated environments. 


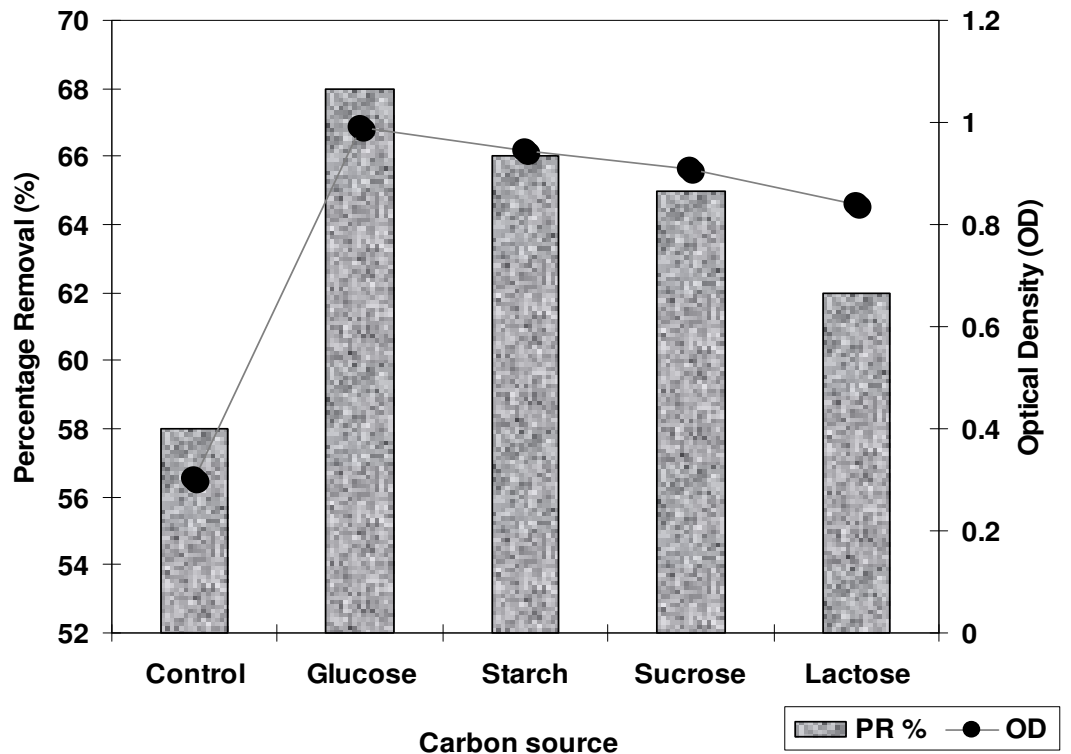

Acknowledgement: T Fig.5 Effect of carbon source on the growth and removal of phosphate by Pseudomonas iences, Bharathiar Universit! sp YLW-7 in synthetic phosphate wastewater

\section{REFERENCES}

American Public Health Association (1998). In: Standard Methods for the Examination of Water and Wastewater, 20th ed. APHA, Washington, DC.

Asea, PEA, Kucey, RMN, Stewart, JWB (1988). Inorganic phosphate solubilization by two

Pencillium sp. In solutions culture and soil. Soil Biology and Biochemistry,20: 459- 464.

Bouquet, PL, Manoil, C, Beckwith, J (1987). Use of Tn pho A to detect genes for exported protein in Escherichia coli. Identification of the plasmid encoded gene for a periplasmic acid phosphatase. Journal of Bac teriology, 169: 1663-1669.

Buchanan, RE, Gibbons, NE (1994). Bergey's Manual of Determinative Bacteriology, $9^{\text {th }}$ ed. William and Wilkins Publishers, Baltimore.

Environmental Protection Agency (1991). National primary drinking water regulations; final rule. 40 CFR Parts 141'142 and 145.Federal Register 56, 20: $3526-97$.

Illmer, P, Schinner, F (1992). Solubilization of inorganic phosphates by microorganisms isolated from forest soils. Soil Biol. Biochem., 24: 389-395.

Illmer, P, Barbato, A, Schinner, F (1995). Solubilization of hardly-soluble aluminium phosphate with phosphorus solubilizing microorganism. Soil Biol. Biochem., 27(3): 265-270.

Jeon, CO, Park, JM (2000). Enhanced phosphorus removal in a sequencing batch reactor fed with glucose as a sole carbon source. Water Res., 34: 2160-2170.

Keasling, JD, Hupf, GA (1996). Genetic manipulation of polyphosphate metabolism affects cadmium tolerance in Escherichia coli. Appl. Environ. Microbiol. 62:743-746.

Kim, KY, Jordan D, Mcdonald, GA (1998). Enterobacter agglomerans, phosphate solubilizing bacteria and microbial activity in soil: effect of carbon sources. Soil Biol. Biochem., 30: 995-1003.

Kornberg, A, 1995. Inorganic polyphosphate: toward making a forgotten polymer unforgettable. J. Bacteriol. 177: 491-496.

Malacinski, GM, Konetzka, WA, (1967). Orthophosphite-nicotinamide adenine dinucleotide oxidoreductase from Pseudomonas fluorescens. J. Bacteriol., 93: 1906- 1910.

Mullan, A, Quinn, JP, McGrath, JW (2002). Enhanced phosphate uptake and polyphosphate accumulation in Burkholderia 
cepacia grown under low-pH conditions. Microbial Ecol., 44: 69-77.

Reyes, I, Bernier, L, Simard, R, Antoun, H (1999). Effect of nitrogen source on the solubilization of different inorganic phosphates by an isolate of Penicillium rugulosum and two UV- induced mutants. FEMS Microbiol. Ecol., 28: 281-290.

Saxena, MM (1994). Environmental Analysis Water, Soil and Air. Agro Botanical Publishers (India).

Torriani-Gorini, A (1987). The birth and growth of the phoregulation. In phosphate metabolism and regulation in microorganisms. American Society for Agronomy press, Madison. 3-11.

Seviour, RJ, Mino, T, Onuki, M (2003). The microbiology of biological phosphorus removal in activated sludge systems, FEMS Microbiol. Rev. 27: 99-127.

U.S. EPA (2001). Memorandum: Development and Adoption of Nutrient Criteria into Water Quality Standards.Online at http://oaspub.epa.gov/waters.

U.S. EPA (2001). National Section 303(d) List Fact Sheet. Online at http:// iaspub.epa.gov/waters/ national_rept.control. 